\title{
UFPR
}

proec

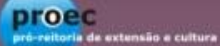

参

and

\section{APRESENTAÇÃO DA METODOLOGIA CIENTIFICA A ESTUDANTES DO ENSINO TÉCNICO ATRAVÉS DA EXPERIMENTAÇÃO EM QUÍMICA ${ }^{1}$}

\author{
Maria Aparecida Bison Gomes², Regina Maria Queiroz de Mello², Liliana \\ Micaroni, José Luis Guimarães ${ }^{3}$
}

\begin{abstract}
${ }^{1}$ Aceito para Publicação no $1^{\circ}$ Semestre de 2015
2Departamento de Química na Universidade Federal do Paraná- UFPR, gomes@ufpr.br, rmqm@ufpr.br,micaroni@ufpr.br

${ }^{3}$ Setor de Educação Profissional e Tecnológica- SEPT da Universidade Federal do Paraná- UFPR, jlguimaraes@ufpr.br
\end{abstract}

\section{RESUMO}

Uma das atividades dos cursos de nível técnico em química é a realização de um estágio onde o estudante se insere em alguma rotina industrial ou realiza atividades de laboratório numa instituição de ensino. No intuito de oferecer outra forma de estágio aos estudantes e ao mesmo tempo proporcionar o aprendizado relacionado à introdução da atividade de pesquisa científica, o objetivo deste trabalho foi oportunizar aos estudantes do ensino técnico o desenvolvimento de uma atividade experimental de seu interesse na área de química baseada na metodologia científica. O público-alvo deste trabalho foram estudantes de duas Instituições da rede pública de Ensino de Curitiba, CEEP e SEPT. Cada estudante desenvolveu um plano de trabalho individual e foi acompanhado, em suas atividades, por um bolsista da Universidade Federal do Paraná. As atividades desenvolvidas para cada estudante consistiram nas seguintes etapas: i) realização de pesquisa bibliográfica; ii) escolha e execução 
de um experimento; iii) preparação de um relatório escrito e iv) apresentação de um seminário ao final das atividades. Aplicamos um questionário de avaliação e constatamos que o projeto foi muito bem avaliado pelos estudantes, transformando a visão de execução de um trabalho laboratorial e despertando o interesse pela pesquisa científica. Por outro lado os bolsistas também se sentiram imensamente recompensados pelas experiências adquiridas tanto na área científica quanto na área de ensino.

Palavras- chave: estágio, metodologia científica, experimentos de química, ensino técnico

INTRODUÇÃO:

Os estudantes de nível médio demonstram grande interesse e curiosidade quando são convidados a desenvolver atividades de laboratório. $O$ processo de ensino e aprendizagem de química melhora substancialmente quando se faz intervenções experimentais e/ou visitas técnicas, dirigidas a um conteúdo especifico (CARVALHOet al, 2007; SANTANA, 2011). Relacionar os conteúdos trabalhados em sala de aula com os experimentos executados no laboratório ajudam os estudantes no entendimento dos fenômenos do dia-adia, desperta a curiosidade e o interesse cientifico nas elucidações e explicações de um fato observado e auxilia no aspecto crítico. $O$ aprofundamento dos conhecimentos proporciona ao estudante encontrar a multidisciplinaridade entre as ciências. Assim sendo, o estudante será um questionador (FREIRE, 2003) e formador de opiniões que o ajudará a expandir seu raciocínio através de construções contínuas e renovadas a partir do real (do cotidiano).

Para a maioria dos estudantes, o ensino da química é considerado difícil e normalmente a química é apresentada pelos docentes através de leis e fórmulas que estão distantes da realidade dos alunos (FRANCISCO, 2005).Por outro lado, a química vem se desenvolvendo no campo cientifico-tecnológico com contribuições significativas.Sua importância se dá através de metodologias 
mais eficientes no desenvolvimento da aprendizagem. No entanto, esta mudança deverá ser gradual ao decorrer das séries sequenciais, e não ocorrer drasticamente do ensino atualmente aplicado nas escolas públicas,devendo se tornar mais efetiva à participação dos envolvidos(MAAR, 2000).

A Educação Profissional Técnica de Nível Médio, mais conhecida como curso técnico, é uma modalidade de educação profissional destinada a alunos matriculados ou vindos do ensino médio, com o objetivo de proporcionar habilitação ou qualificação profissional técnica de nível médio, segundo perfil profissional de conclusão. No caso específico de curso técnico em química ou áreas afins, a experimentação em química é de grande relevância para sua qualificação profissional.

Em Curitiba existem diversas Instituições Públicas de Ensino que oferecem cursos de nível técnico em química ou áreas afins. Dentre elas podemos citar: a) o Centro Estadual de Educação Profissional de Curitiba (CEEP) com os cursos de Técnico em Química Industrial e Técnico em Meio Ambiente, b) a UFPR - Setor de Educação Profissional e Tecnológica (SEPT) com o curso de Técnico em Petróleo e Gás Natural e c) Colégio Estadual Francisco Zardo; Colégio Estadual Homero Baptista Barros; Colégio Estadual Paulo Leminski e Colégio Estadual Prof. Elysio Vianna que ofertam o Curso Técnico em Meio Ambiente.

Uma das atividades dos cursos de nível técnico em química ou áreas afins é a realização de um estágio onde o estudante se insere em alguma atividade industrial ou em uma instituição de pesquisa/ensino e desenvolve atividades de interesse destas instituições. No intuito de oferecer outra forma de estágio, o objetivo do projeto de Extensão Universitária "Pensando e Fazendo Ciência" (registro 751/12 na PROEC/UFPR) é oportunizar e incentivar os estudantes do ensino técnico e/ou médio integrado a desenvolver uma atividade experimental de seu interesse na área de química utilizando a metodologia científica. 


\section{METODOLOGIA}

Em maio de 2012 o projeto "Pensando e Fazendo Ciência" foi divulgado em duas instituições de ensino técnico de nível médio: CEEP e SEPT. Um total de 48 estudantes se inscreveu e respondeu um questionário. Os questionários foram analisados pelos quatro professores da UFPR envolvidos no projeto e as respostas dos estudantes foram agrupadas nos seguintes assuntos: corantes, análise de alimentos, reciclagem, biodiesel e fitoterápicos.Algumas das respostas não puderam ser atendidas por falta de condições de realização do trabalho na área de interesse do estudante, como por exemplo em polímeros, lâmpadas fluorescentes, fabricação de bebidas, cimento e microbiologia. Tais estudantes foram convidados a participar de alguma proposta do grupo atendido. Outro grupo de estudantes optou por realizar estágio em estabelecimentos comerciais (indústria, farmácia, etc). Assim, de um total de 48 estudantes inscritos, o projeto atendeu a 25 estudantes, no período de 1 ano.

Cada um dos quatro professores orientadores da UFPR solicitou a um bolsista uma pesquisa bibliográfica sobre um dos assuntos selecionados. Esta pesquisa foi realizada em diferentes fontes de dados científicos, a saber: JournalofChemicalEducation, Química Nova, Química Nova na Escola, Associação Brasileira de Normas Técnicas (ABNT) e em Banco de Patentes Nacionais (sitio do INPI) e teve como finalidade identificar experimentos que 0 estudante do ensino técnico pudesse realizar nas condições disponíveis no Laboratório de Extensão em Química no assunto de seu interesse. O resultado da pesquisa bibliográfica foi apresentado ao estudante, definido o plano de trabalho e providenciado o Termo de Compromisso para que o estudante pudesse registrar esta atividade como estágio obrigatório. Para os estudantes do CEEP o tempo de permanência no projeto foi de 80 horas e para 0 estudante do SEPT foi de 240 horas. Para cada estudante foi definido umaatividade experimental diferente dentro de um determinado assunto e ele foi atendido individualmente pelos bolsistas. Cada estudante realizou atividades de pesquisa bibliográfica e execução do experimento no laboratório, com o auxílio do bolsista. Após a realização do plano de trabalho o estudante escreveu um relatório e apresentou um seminário. 
Antes e após o estudante executar o plano de trabalho eles responderam um questionário com questões fechadas agrupadas nos seguintes assuntos: i) busca de informação: em livros, internet, artigos científicos, normas técnicas e patentes, ii) trabalho no laboratório: incluindo conhecimentos sobre manuseio de vidrarias, processos laboratoriais, equipamentos, segurança no laboratório, interpretação dos resultados, formalidade de um relatório científico e apresentação oral, iii) satisfação em participar do projeto, iv) indicação do projeto a outro estudante, e, v) interesse em realizar outro trabalho em um assunto diferente.

As atividades relacionadas à pesquisa bibliográfica foram realizadas no Laboratório de Informática do SEPT e a execução da parte experimental foi realizada no Laboratório de Extensão em Química do Departamento de Química da UFPR.

A dinâmica de realização do projeto obedeceu à sequência de ações esquematizada na Figura 1, que aborda desde a divulgação do projeto nas escolas ea realização do experimento até a avaliação do projeto. 


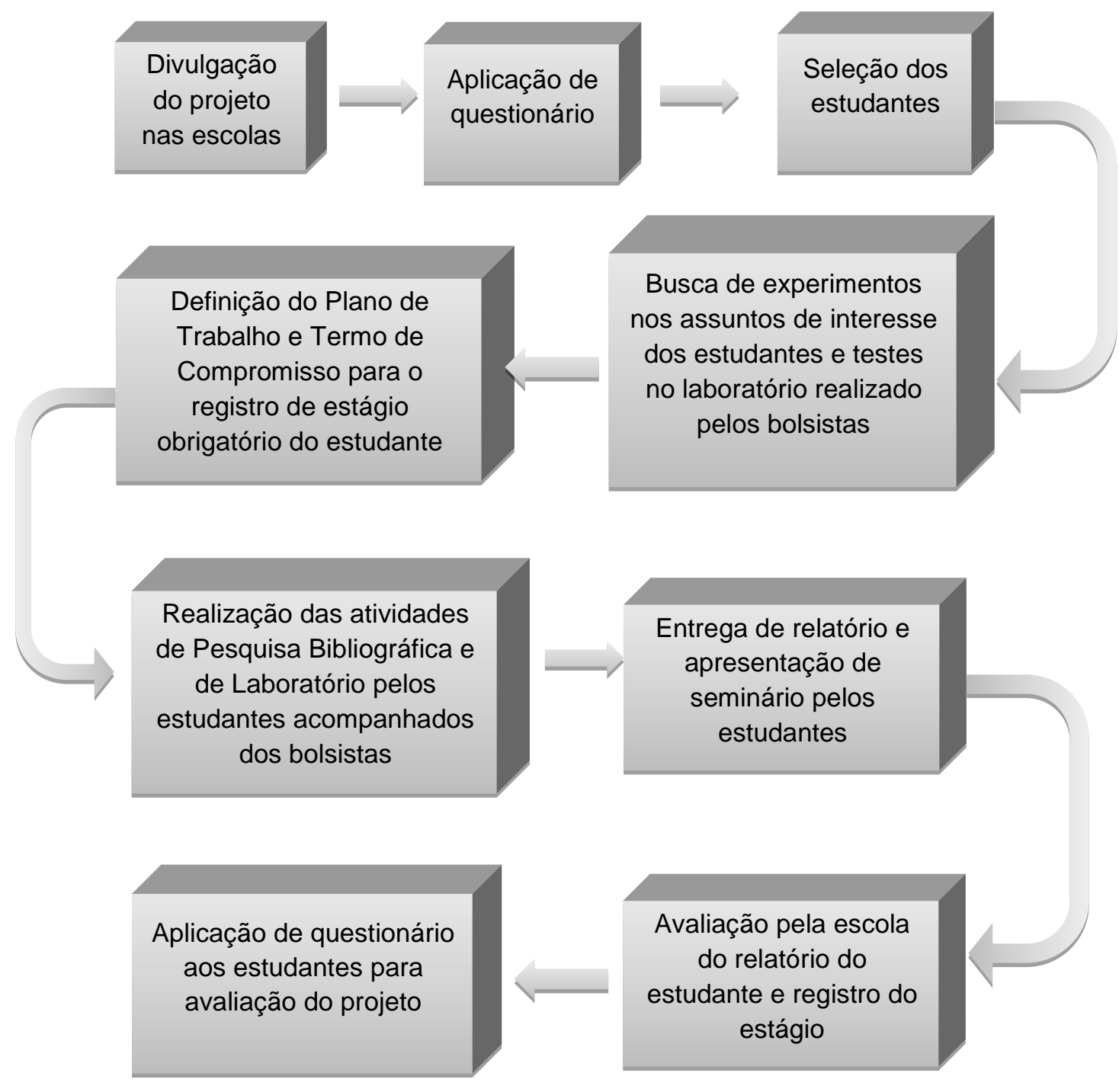

FIGURA 1 - FLUXOGRAMA DA DINÂMICA DA EXECUÇÃO DO PROJETO

\section{RESULTADOS E DISCUSSÃO}

$\mathrm{Na}$ Tabela 1 apresentamos os temas e o título do plano de trabalho realizado pelos estudantes no primeiro ano de vigência deste projeto.

TABELA 1: TEMAS E TÍTULO DOS PLANOS DE TRABALHO DESENVOLVIDOS POR CADA ESTUDANTE. 


\begin{tabular}{|c|c|}
\hline Tema & Título do Plano de Trabalho do estudante \\
\hline \multirow{7}{*}{ Corantes } & Extração de corantes alimentícios \\
\hline & Indicadores de $\mathrm{pH}$ naturais de flores \\
\hline & Indicadores de pH naturais de beterraba e repolho roxo. \\
\hline & Extração alcoólica de corantes naturais de flores \\
\hline & $\begin{array}{l}\text { Indicadores de } \mathrm{pH} \text { naturais de uva e cipó corda de } \\
\text { viola. }\end{array}$ \\
\hline & $\begin{array}{l}\text { Corantes naturais: extração e uso no tingimento de } \\
\text { tecidos }\end{array}$ \\
\hline & $\begin{array}{l}\text { Extração de corante natural para utilização como } \\
\text { indicador ácido base }\end{array}$ \\
\hline \multirow{6}{*}{ Análise de alimentos } & Análise de chá \\
\hline & Análise de bebidas \\
\hline & Análise de farinha de trigo (fosfatos) \\
\hline & $\begin{array}{l}\text { Análise de farinha de trigo (glúten, glicídios, umidade, } \\
\text { acidez) }\end{array}$ \\
\hline & Cafeína: suas propriedades \\
\hline & $\begin{array}{l}\text { Determinação de ácido ascórbico em produtos } \\
\text { alimentícios }\end{array}$ \\
\hline \multirow{5}{*}{ Reciclagem } & Produção de sabonete líquido a partir de óleo vegetal \\
\hline & Pré-purificação da glicerina e aplicações \\
\hline & Reciclagem de jornal \\
\hline & Reciclagem de embalagens multicamada (longa vida) \\
\hline & $\begin{array}{l}\text { Reciclagem de embalagens plásticas flexíveis para } \\
\text { alimentos multicamada }\end{array}$ \\
\hline \multirow{5}{*}{ Biodiesel } & Síntese de Biodiesel a partir de óleo de fritura \\
\hline & Síntese de Biodiesel a partir de Óleo de soja \\
\hline & Síntese de Biodiesel a partir de Óleo de milho \\
\hline & Síntese de Biodiesel a partir de Óleo de girassol \\
\hline & Caracterização de Biodiesel \\
\hline \multirow[t]{2}{*}{ Fitoterápicos } & Preparação e caracterização de tintura de guaco \\
\hline & Preparação e caracterização de tintura de calêndula \\
\hline
\end{tabular}

Pelo fato de que cada estudante de curso técnico desenvolveu seu próprio projeto e foi acompanhado de forma individual pelos bolsistas graduandos de química, a nossa proposta atendeu a apenas 25estudantes de nível técnico no primeiro ano. Numa primeira análise, esse número parece reduzido, mas não o é, uma vez que o atendimento ao estudante e o plano de trabalho foi individual.

Antes e após a realização do trabalho, aplicamos um questionário de avaliação onde os estudantes deveriam expressar se houve contribuição ou melhora à sua formação profissional em vários aspectos, os quais serão 
analisados a seguir. Cumpre acrescentar que a escala utilizada, em termos do nível de conhecimento, foi a seguinte: 0 - Nulo; 1 - Insuficiente; 2 - Regular; 3 - Bom; 4 - Muito Bom; 5 - Ótimo.

\section{Busca de informações em base de dados científicos}

Pode-se constatar, com base na Figura 2, que os estudantes do curso técnico tiveram um aprendizado eficiente na metodologia de busca de informações científicas uma vez que antes da realização do curso, 50\% deles não conheciam a pesquisa científica; após o curso ministrado esse número aumentou para $98 \%$. Depoimentos de alguns estudantes foram bastante gratificantes, pois disseram de forma espontânea que tinham aprendido a fazer pesquisa científica na internet.

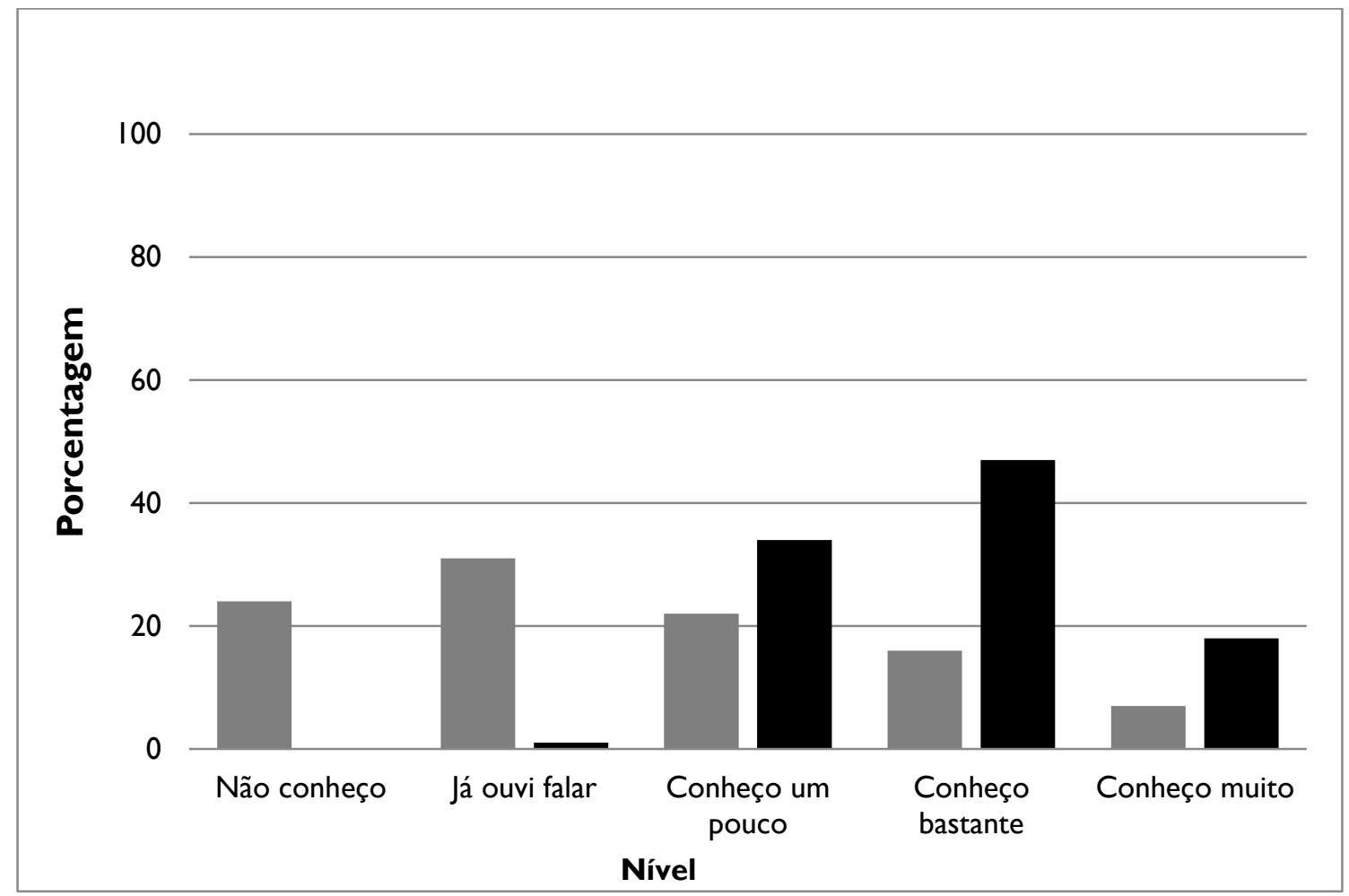

FIGURA 2 - NÍVEL DE CONHECIMENTO DOS ESTUDANTES DOS CURSOS TÉCNICOS EM BUSCA DE INFORMAÇÕES CIENTÍFICAS ANTES (CINZA) E APÓS (PRETO) O CURSO.

2. Execução experimental do trabalho 
Com base na Figura 3verificamos que antes da realização das atividades de estágio, apenas $30 \%$ dos estudantes se consideravam aptos ao manuseio correto de vidrarias; após o estágio esse número aumentou para 90\% considerando os níveis de conhecimento classificados como muito bom e ótimo.

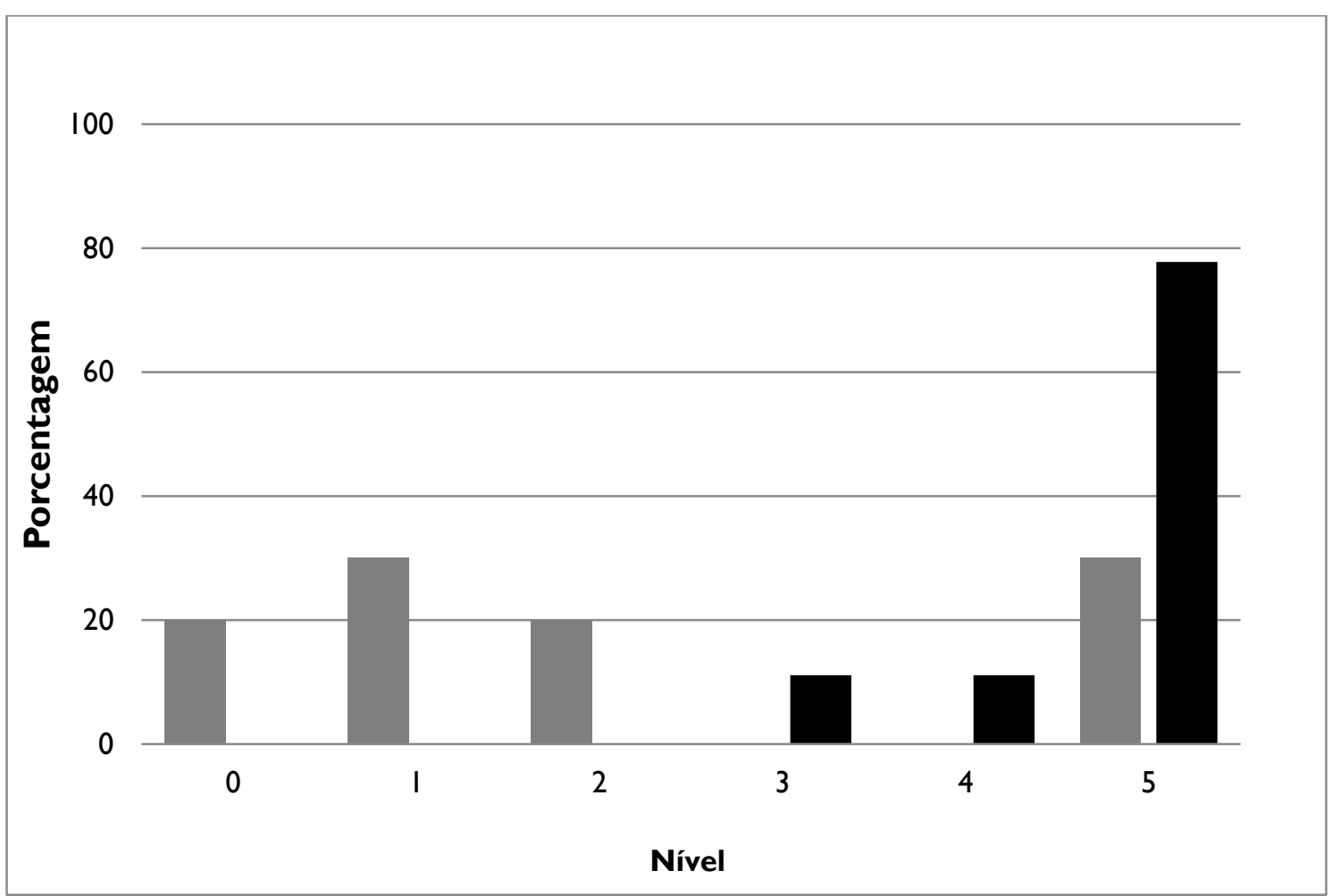

FIGURA 3 - NÍVEL DE CONHECIMENTO COM RELAÇÃO AO MANUSEIO DE VIDRARIAS ANTES (CINZA) E APÓS (PRETO) A EXECUÇÃO DO EXPERIMENTO.

Análise similar pode ser feita com base na Figura 4, onde verificamos que antes da realização das atividades de estágio, apenas $20 \%$ dos estudantes se consideravam aptos ao manuseio correto de instrumentos e equipamentos de laboratório; após o estágio esse número aumentou para praticamente 100\%. 


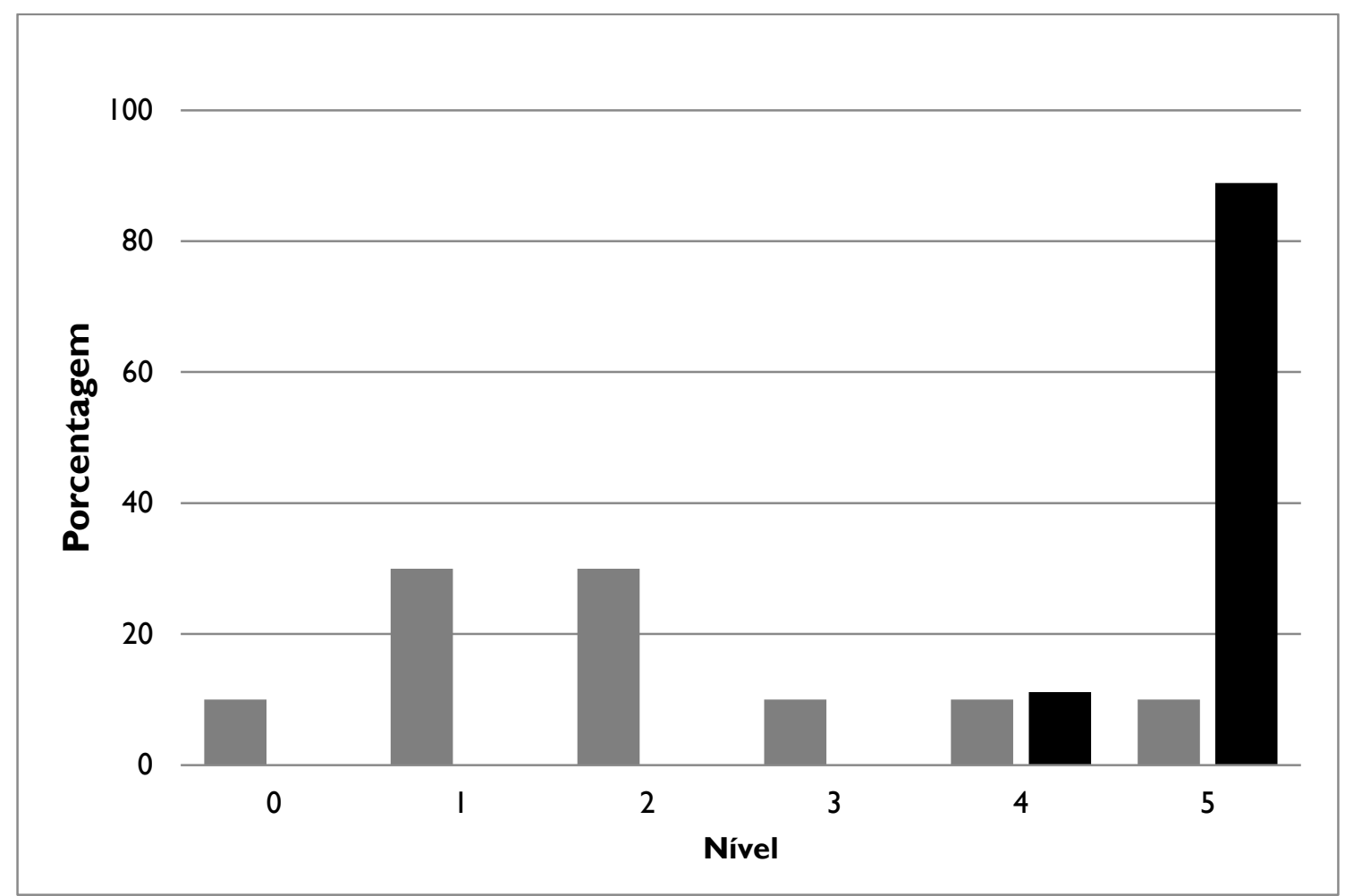

FIGURA 4 - NÍVEL DE CONHECIMENTO SOBRE INSTRUMENTOS E EQUIPAMENTOS DE LABORATÓRIO ANTES (CINZA) E APÓS (PRETO) A EXECUÇÃO DO EXPERIMENTO.

Analisando a Figura 5, verificamos que um número razoável de estudantes (40\%) tinha um bom conhecimento sobre segurança no laboratório antes da realização das atividades de estágio. Após o término das atividades,cerca de $30 \%$ destes estudantes migraram a sua resposta para os níveis de conhecimento muito bom e ótimo. Desta forma ao final da atividade experimental cerca de $90 \%$ dos estudantes responderam ter conhecimento nos níveis muito bom e ótimo.

A análise das Figuras 3 a 5 mostra resultados extremamente positivos do projeto, uma vez que o grau de conhecimento adquirido na realização da parte experimental foi bastante elevado. 


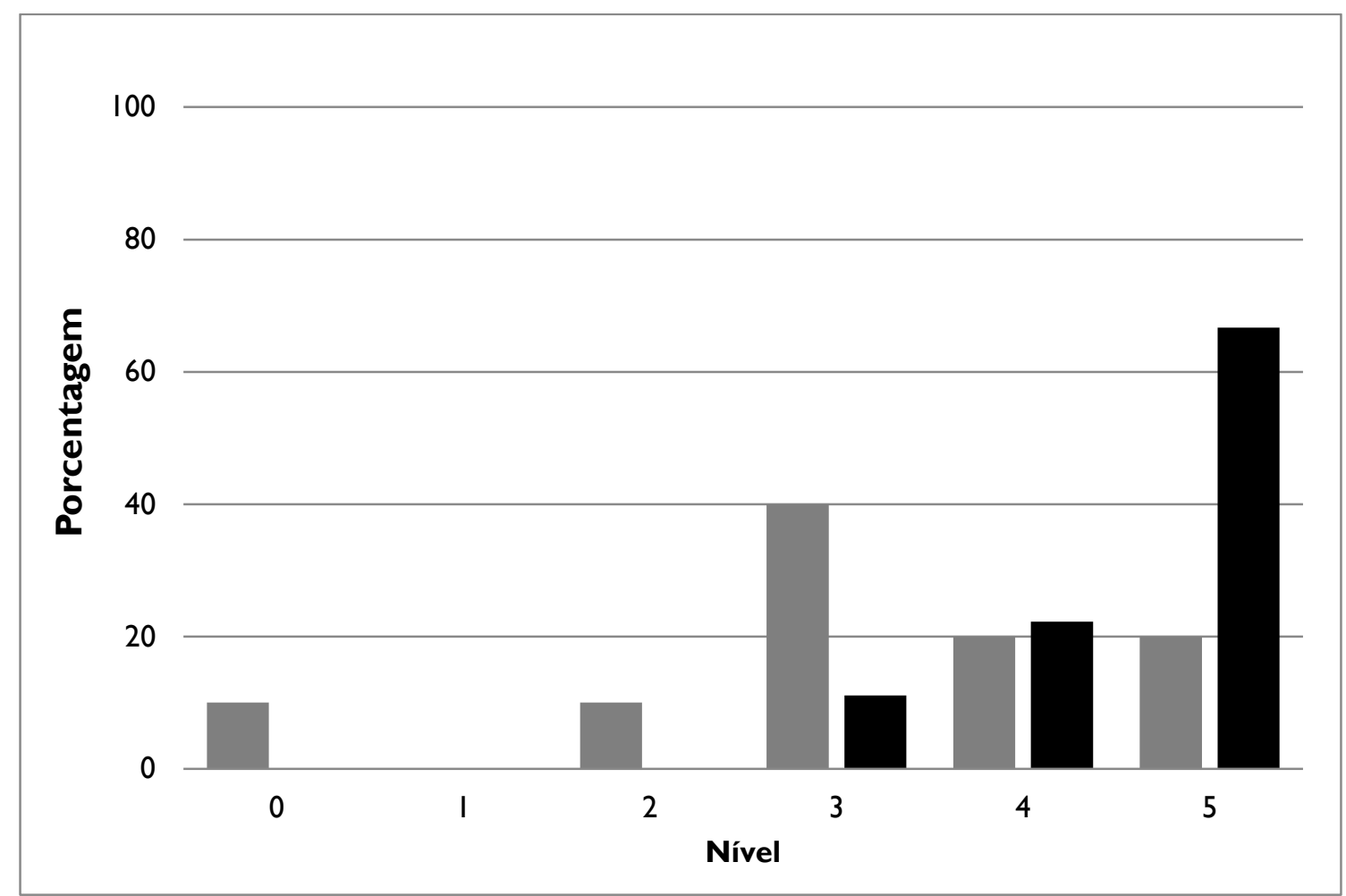

FIGURA 5 - NÍVEL DE CONHECIMENTO EM SEGURANÇA NO LABORATÓRIO ANTES (CINZA) E APÓS (PRETO) O PROJETO.

3. Capacidade de interpretar e apresentar os resultados na forma escrita e oral.

A Figura 6 mostra que existia cerca de 10\% dos estudantes no nível 1 (insuficiente) antes de realizar a atividade experimental em relação à capacidade de interpretar os resultados. Ao término das atividades este percentual migrou para os níveis entre 3 a 5 (bom, muito bom e ótimo) indicando que os estudantes aprenderam a pensar e interpretar os resultados obtidos no laboratório. Ao final do projeto aproximadamente $85 \%$ dos estudantes responderam estar nos níveis 4 e 5 . Esse resultado é muito bom porque experimentos de química realizados sem uma interpretação adequada não agregam conteúdo algum à formação do estudante. Como a capacidade de interpretação aumentou significativamente, sentimo-nos gratificados com relação a mais esse aspecto. 


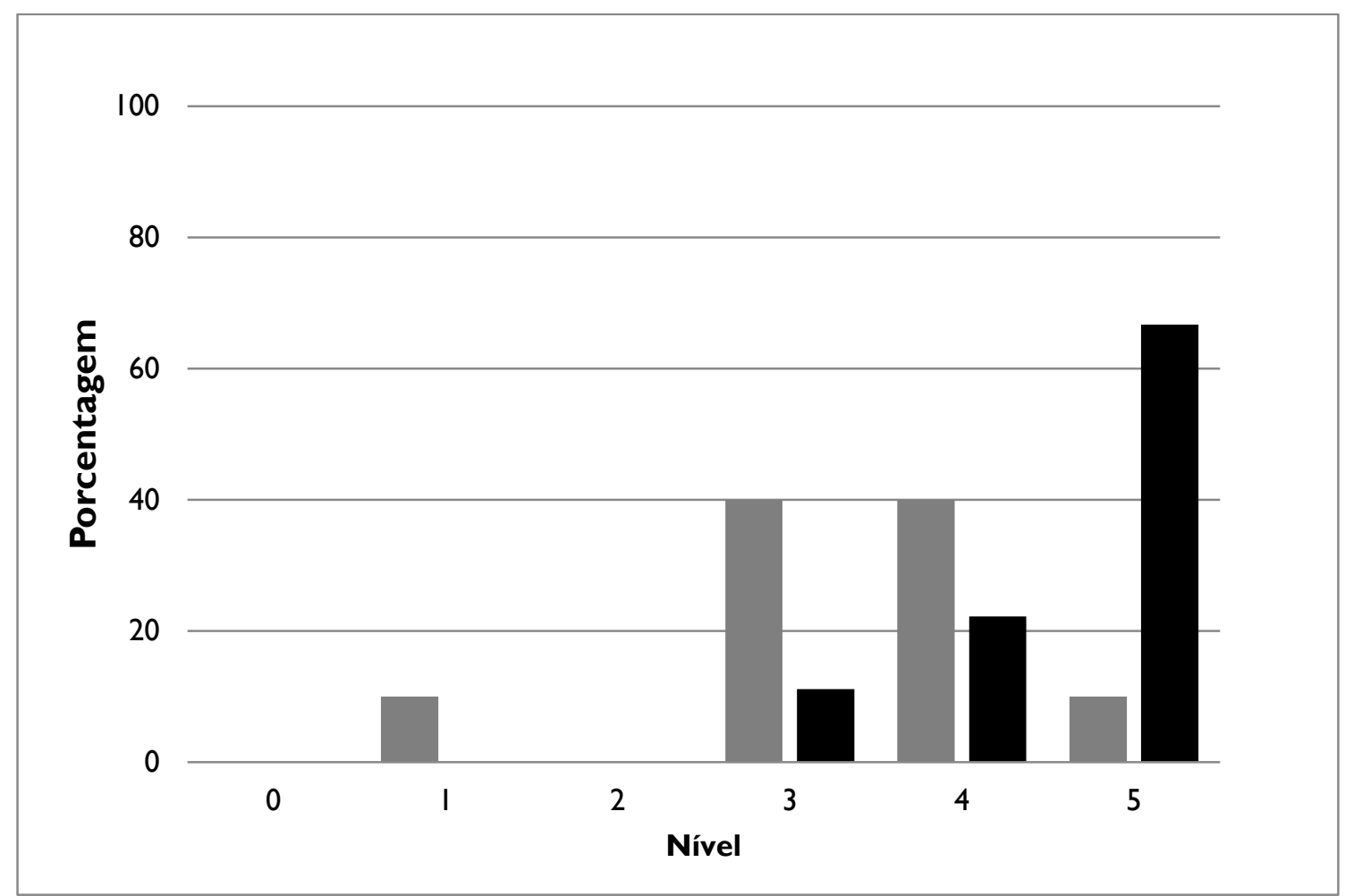

FIGURA 6 - CAPACIDADE DE INTERPRETAR RESULTADOS ANTES (CINZA) E APÓS (PRETO) A REALIZAÇÃO DE UM EXPERIMENTO

A avaliação dos estudantes quanto à sua capacidade de organizar os resultados na forma escrita (relatório) está mostrado na Figura 7. A porcentagem de estudantes que haviam respondido nos níveis 2 e 3 (regular e bom) passou de $40 \%$ para $10 \%$ antes e após participarem das atividades do projeto, respectivamente. Ao final do projeto $85 \%$ dos estudantes se classificaram nos níveis 4 e 5 (muito bom e ótimo). 


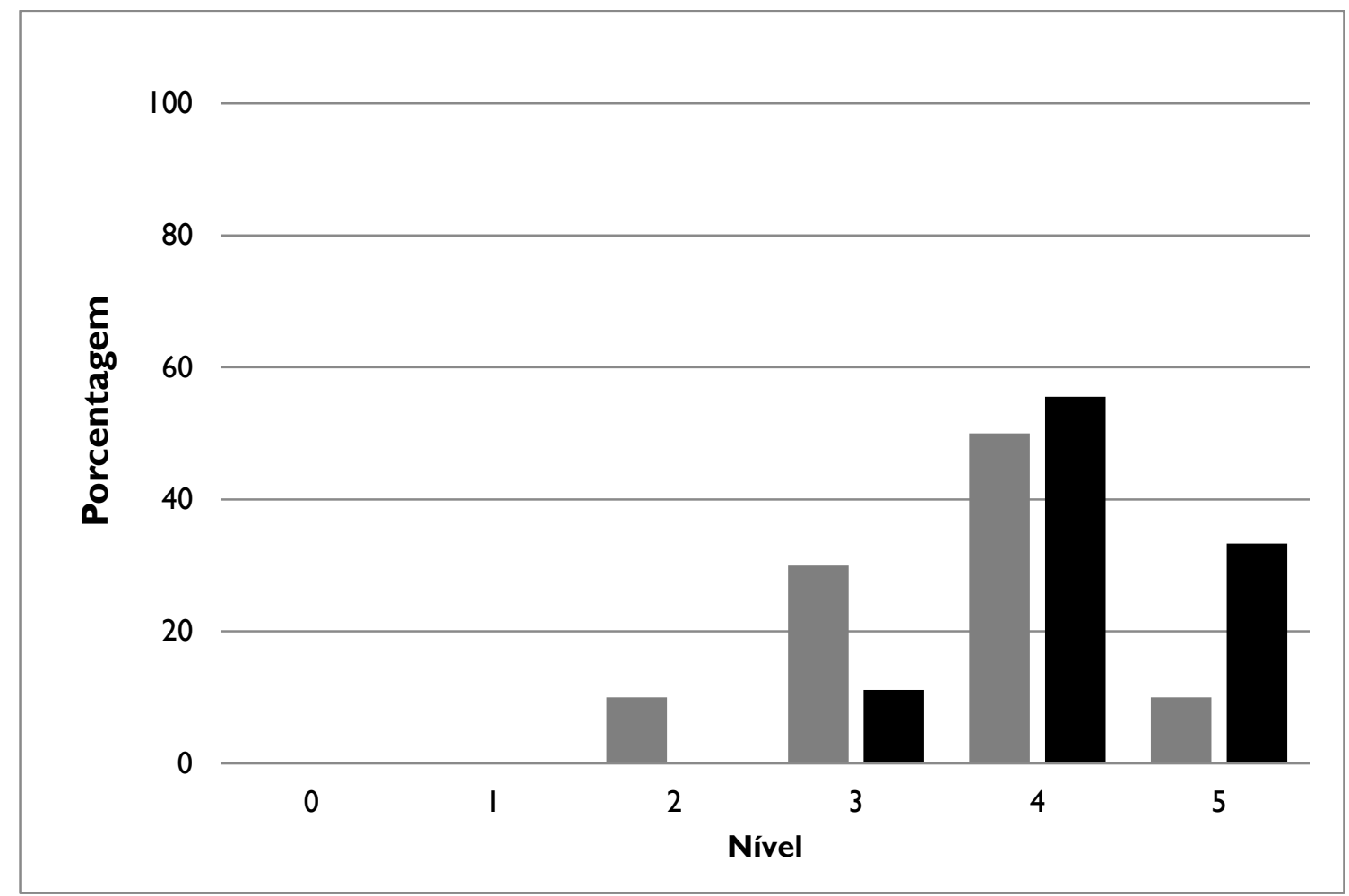

FIGURA 7 - CAPACIDADE DE ORGANIZAÇÃO DOS RESULTADOS NA FORMA ESCRITA ANTES (CINZA) E APÓS (PRETO) A EXECUÇÃO DO EXPERIMENTO.

A Figura 8 mostra o único indicador que teve piora após a realização do estágio. Antes da realização do estágio, 50\% dos estudantesindicou ter controle das emoções durante as apresentações orais. Após a realização do estágio, esse número caiu para $20 \%$. Acreditamos que esse fato ocorreu porque os estudantes se sentiram inseguros por estarem fora do ambiente escolar habitual e terem que apresentar um seminário para uma plateia mista, composta de estudantes de diferentes instituições de ensino, professores universitários e alguns professores das escolas de ensino médio. 


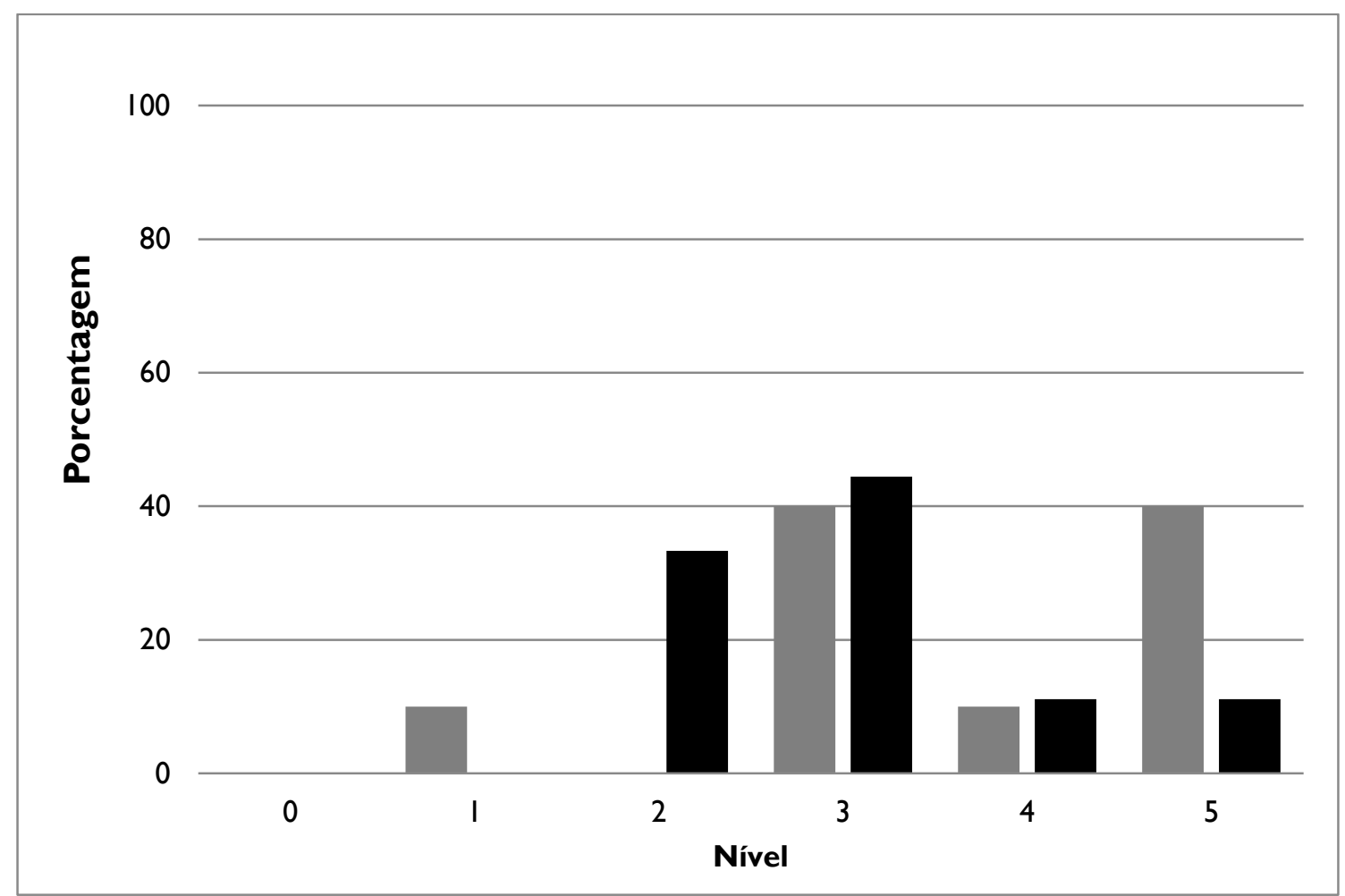

FIGURA 8 - CAPACIDADE DE CONTROLE DA TIMIDEZ/ANSIEDADE/NERVOSISMO DURANTE APRESENTAÇÕES NA FORMA ORALANTES (CINZA) E APÓS (PRETO) A EXECUÇÃO DO EXPERIMENTO.

\section{CONSIDERAÇÕES FINAIS:}

Analisando as respostas do questionário, observamos que os estudantes avaliaram positivamente $\mathrm{o}$ trabalho realizado pela equipe de profissionais $\mathrm{e}$ acrescentaram que a participação foi contributiva à sua formação em termos dos itens constantes no questionário. Outro ponto positivo foi a satisfação pessoal que os estudantes demonstraram em relação à nossa proposta (inovadora e diferente) e se a indicaria a alguém. Todos se mostraram satisfeitos e dispostos a indicar a nossa proposta para um colega.

Com a realização deste trabalho, durante o período de um ano até o momento, constatamos que, quando o estudante é convidado a desenvolver um tema de seu interesse, voltado ao aprendizado de química, há contribuição em diversas atividades complementares que se inicia na pesquisa bibliográfica, passando pela experimentação no laboratório, organização dos resultados na forma escrita e divulgação dos resultados na forma oral, além da melhora no desempenho escolar. 
Concluímos que a inserção da metodologia científica no trabalho de laboratório contribuiu na complementação da formação acadêmica do estudante do ensino técnico/médio integrado, transformando a sua visão de execução de um trabalho laboratorial e despertando o interesse pela pesquisa científica. Estes estudantes tiveram a oportunidade de interagir diretamente com professores universitários e graduandos do curso de química durante a realização de seu experimento, o que contribuiu para o interesse destes em se qualificar ainda mais profissionalmente. Além disso, os bolsistas graduandos adquiriram experiências simultâneas na área científica e na área de ensino e também se mostraram bastante satisfeitos em participar do projeto.

Agradecimentos:

Agradecemos à Universidade Federal do Paraná pela infra-estrutura e pelaconcessão de bolsas de extensão e de permanência, às instituições CEEP (Centro Estadual de Educação Profissional de Curitiba) e SEPT (Setor de Educação Profissional e Tecnológica) pela confiança em nós depositada e aos bolsistas de graduação: Ana Paula Brum, Cinthia T. Roza, Erna G. A. Oliveira, Gabriel A. Lopes, Jean P. Weiss, Mayara P. dos Santos, Sara L. S. da Rocha, Stephanie A. Todesco, Virgínia K. F. de Jesus e Yohanna B. Lacerda.

\section{REFERÊNCIAS}

CARVALHO, Hudson Wallace Pereira; BATISTA, Ana Paula de Lima; RIBEIRO, Cláudia Maria.Ensino e aprendizado de química na perspectiva dinâmico-interativa. Experiências em Ensino de Ciências - v2(3), p. 34-47, 2007.

FRANCISCO JÚNIOR, WilmoErnesto. A Experimentação e o Dia-a-Dia no Ensino de Química. XIX ENCONTRO REGIONAL DA SOCIEDADE BRASILEIRA DE QUÍMICA, Ouro Preto,2005 (CD-ROM). 
FREIRE, Paulo. Pedagogia da autonomia. 35 ed. Editora: Paz e Terra, 2003. $148 \mathrm{p}$.

MAAR, Juergen Heinrich.Glauber, Thurneisser e Outros.Tecnologia química e química fina, conceitos não tão novos assim. Química Nova, São Paulo, v. 23, n. 5, p. 709-713, 2000.

SANTANA,Joselaine Carvalho;SANTOS,Clédson;CARVALHO,Luana Cunha.A experimentação no ensino de química e física: concepções de professores e alunos do ensino médio.V COLÓQUIO INTERNACIONAL "EDUCAÇÃO E CONTEMPORANEIDADE", São Cristovão- SE-Brasil, 21 a 23/09/2011. 